\title{
Solid rheological properties of PBT-based vitrimers
}

L. Farge ${ }^{1 *}$, S.Hoppe $^{2}$, V. Daujat ${ }^{1,2}$, F. Tournilhac ${ }^{3}$, S. André ${ }^{1}$

1 Université de Lorraine, CNRS, LEMTA, F-54000 Nancy, France

2 Université de Lorraine, CNRS, LRGP, F-54000 Nancy, France

3 Molecular, Macromolecular Chemistry, and Materials, ESPCI Paris, PSL Research University, 10 Rue Vauquelin, F-75005 Paris, France

*Corresponding author: laurent.farge@univ-lorraine.fr

TOC

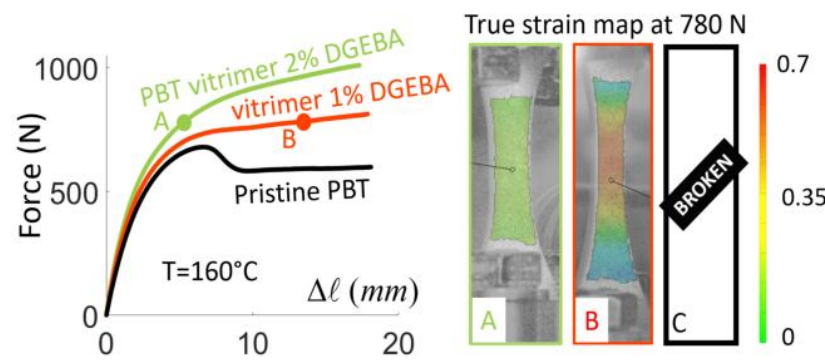

For Table of Contents use only

\section{Abstract}

We present an experimental investigation of the mechanical properties of solid vitrimer samples obtained by incorporating a diepoxide into a commercial PBT in the presence of a $\mathrm{Zn}(\mathrm{II})$ catalyst using batch compounder and injection molding machines. Tensile experiments were carried out at different temperatures $\left(80^{\circ} \mathrm{C}, 120^{\circ} \mathrm{C}, 160^{\circ} \mathrm{C}\right)$ below the melting point $\left(220^{\circ} \mathrm{C}\right)$ and with various diepoxide concentrations $(0,1,2 \mathrm{wt} \%$,$) . We found that vitrimer$ plastic deformation mechanisms differ drastically from those of the PBT precursor, and more generally from the regular behaviour of other semi-crystalline polymers. In PBT vitrimers, strain localization (necking) is very weak and can even be suppressed. This type of behaviour is due to the increase in strain hardening caused by vitrimer crosslinking. The creep resistance and stiffness of PBT vitrimers are significantly higher than that those of the pristine PBT. We found that vitrimer modification of PBT at moderate levels improves dimensional stability without inducing brittleness. These promising results highlight the need to find processes which enable significant 
production levels of these new materials. In the perspective section, we briefly present a way to produce PBTbased vitrimers using CRE (Continuous Reactive Extrusion).

\section{Introduction}

Vitrimers were introduced in the beginning of the 2010s and are chemically crosslinked polymers characterized by the presence of exchangeable links. ${ }^{1-3}$ This feature allows topology changes while maintaining the integrity of the network (see Denissen et al. and Van Zee et al. for review articles ${ }^{4,5}$ ). The bond exchange is thermally activated and takes places according to an "associative" scheme corresponding to a substitution reaction between a pendent reactive group within the network and an existing cross-link. ${ }^{6,7}$ This exchange mechanism implies that the number of covalent bonds (or cross-links) remains constant after the synthesis step. The general concept of vitrimers implies exchange reactions are at work but this is in no way bound to any particular chemistry or even to a particular type of network. Prototypes were based on bond exchange through metal catalyzed transesterifications and synthesized from multifunctional monomers, with relevant functions to ensure gelation and establish exchangeable links. Since then a number of catalyzed and catalyst-free exchange reactions have been tested. ${ }^{8-22}$ Furthermore, new vitrimers have been synthesized from polymer precursors by introducing exchangeable chemical cross-links between their chains. ${ }^{13,23-27}$ This second route is particularly appealing because it enables the transformation of commercial thermoplastics into new materials with minimal engineering effort and additionally so because this kind of modification can preserve crystallinity. ${ }^{28}$

The presence of dynamic (as opposed to static) covalent networks whose characteristics depend on the synthesis process parameters gives vitrimers specific and potentially tunable properties ${ }^{29-31}$. This is the main reason why these new materials are considered to be viable solutions to overcome certain weaknesses of existing polymers. When vitrimers are obtained with thermoset precursors at a temperature high enough to allow the activation of the covalent bond migrations, this makes topological modifications of the polymer network possible thus rendering the material malleable. This in turn means it can be shaped and paves the way for recycling processes. ${ }^{1,32}$ In the case of thermoplastic-based vitrimers, if the exchange reaction rate is low at service temperature this gives an enhanced dimensional stability due to crosslinking. Conversely, at processing temperatures a higher rate of exchange reactions means the material remains easy to shape. ${ }^{23,30}$ 
With the exception of shape-memory vitrimer formulations which include a volume fraction of semi-crystalline phase, ${ }^{9,33-36}$ the semi-crystalline vitrimers that have been reported so far have been based on two types of semicrystalline polymer (SCP) precursors: 1) PBT (Poly(butylene terephthalate) $)^{13,30,37}$, the polymer we used in the present study, and 2) PE (Polyethylene) $)^{26,27,38-39}$. The influence of the dynamic permanent covalent network on the rheological properties of SCP-based vitrimers has mainly been studied in the "molten state", i.e. with measurements obtained above the crystal melting temperature $\left(T_{m}\right)$. With DMA (Dynamic Mechanical Analysis) measurements carried out with a temperature sweep, the storage modulus has been found to exhibit a rubbery plateau above $T_{m} \cdot 13,26,27,30,37-38$ The value of the storage modulus on the plateau is mainly governed by the content of cross-linkers added during the vitrimer synthesis. ${ }^{13,27,30,37}$ By contrast, in the case of a neat semi-crystalline polymer, the storage modulus measured by DMA drastically collapses above $T_{m}$ due to the "liquid-like" behaviour of the material in the molten state. The dynamic character of the permanent covalent network can be demonstrated using relaxation experiments which again need to be carried out above $T_{m}$. At such temperatures, the covalent bond exchange process is likely to be activated, which makes full stress relaxation possible even though the material is crosslinked..$^{13,27,37-38}$ Furthermore, it is possible to extract the relaxation times ${ }^{30,37}$ or zero shear viscosities ${ }^{13}$ from the stress relaxation curves and to check that these quantities follow Arrhenius laws which proves that the flow is mainly controlled by the covalent bond exchange kinetics. ${ }^{4}$ The rheological behaviour of SCP-based vitrimers in the "molten state" can also be analyzed from the variations of the storage $\left(G^{\prime}\right)$ and loss $\left(G^{\prime \prime}\right)$ moduli measured by rheometry with temperature or frequency sweeps..$^{6,13,27,30,37,40-41}$ In particular, it is possible to roughly estimate whether a vitrimer has predominantly "rubber" $\left(G^{\prime}>G^{\prime \prime}\right)$ or "viscous" behaviour $\left(G^{\prime \prime}>G^{\prime}\right)$ for a given temperature and time scale. During vitrimer synthesis, the measurement of the temporal increase of $G^{\prime}$ and $G^{\prime \prime}$ also makes it possible to monitor how the crosslinking reaction progresses and find the gelation point, which occurs approximately when $G^{\prime}=G^{\prime \prime} \cdot{ }^{13,40-41}$ After the gelation point, the crosslinking reaction ends and the storage and loss moduli reach constant values with $G^{\prime}>G^{\prime}$. The molten polymer remains then in the "rubbery" state except when destruction of cross-links takes place by thermal degradation. ${ }^{27}$

At service temperatures, i.e. in the solid state or below $T_{m}$, the published results concern mainly the viscoelastic characteristics of vitrimers, or more specifically the creep properties of these materials. Röttger et al. and Caffy et 
al. showed that PE-based vitrimers have a better creep resistance than their HDPE precursors, ${ }^{26-27}$ which can naturally be attributed to crosslinking of these materials. This also implies that the rate of covalent bond exchange remains low at the measurement temperature because, if this were not the case, the material topology modifications of the dynamic covalent network would result in material flowing. In the case of a PBT/glycerolbased vitrimer with $\mathrm{Zn}(\mathrm{II})$ catalyst, Zhou et al. have shown that creep properties can be tuned by controlling the glycerol content and the $\mathrm{Zn}(\mathrm{II}) / \mathrm{glycerol}$ ratio. ${ }^{30}$ The cross-link density is directly related to the former parameter and the dynamics of the exchangeable network to the latter. Regarding the mechanical behaviour of highly deformed solid vitrimers, it was shown using tensile test measurements performed at room temperature that elongation at break of PE vitrimers is smaller than that of their pristine HDPE precursor. ${ }^{27}$ However, there are no published studies which describe the details of the plasticity development in semi-crystalline based vitrimers. This requires at least measuring the true strain-true stress curve which is intrinsic to the material, and performing strain field measurements at the specimen scale in order to study the characteristics of the possible formation of a neck.

To date, despite their promising properties for industrial applications, vitrimers have only been produced in relatively small quantities in chemistry labs. It is therefore a challenge to find processes that would enable the mass production of vitrimers before envisaging the dissemination of these materials. Reactive extrusion is a widely-used process in the polymer industry and has already been used to produce vitrimers from a PBT precursor $^{13}$ and PE-based vitrimers. ${ }^{27,39}$ However the laboratory-scale extruders that were used were equipped with a recirculation channel to control the residence time and production cannot be carried out continuously as is required in industry. Furthermore, it has been shown that progressive material crosslinking causes the viscosity of the melt to increase drastically during the reaction which can lead to blockage of the extruder. ${ }^{13}$ Taplan et al. demonstrated that highly crosslinked vinylogous urethanes vitrimers can be extruded in their fully cured form. ${ }^{42}$ These low viscosity vitrimers were obtained by modifying the distribution of reactive moieties and by selecting an amine functional cross-linker with the aim of increasing the chemical exchange rate. It was possible to achieve stress relaxation times below $1 \mathrm{~s}$ at $150^{\circ} \mathrm{C}$ and cross-over between $G^{\prime}$ and $G^{\prime \prime}$ at time scales and temperatures that are compatible with continuous processes (approximately $130^{\circ} \mathrm{C}$ and $1 \mathrm{rad} / \mathrm{s}$ ). 
Demongeot et al. ${ }^{13}$ have already demonstrated that the mechanical properties of PBT-based vitrimers in the "molten state" were superior to those of their pristine PBT precursor. In this study, our main objective was to assess whether the improvement of vitrimer mechanical behaviour remains observable in the "solid state", between $T_{g}$ and $T_{m}$ and in particular in the range approaching the Heat Deflection Temperature (HDT $\approx 160^{\circ} \mathrm{C}$ for unreinforced $\mathrm{PBT}^{43}$ ). The paper ends with a brief perspective paragraph where we suggest a simple two-stage process allowing significant production of PBT-based vitrimers.

\section{Experimental section}

\subsection{Vitrimer synthesis by non continuous reactive extrusion}

We synthesized vitrimers with a PBT precursor using an experimental procedure developed by Demongeot et al. ${ }^{13}$ The synthesis is based on a catalyzed addition and transesterification chemistry. Crosslinking occurs during the reactive mixture between PBT, a diepoxide and the $\mathrm{Zn}(\mathrm{II})$ catalyst. An antioxidant (Irganox 1010) was also added to the mixture. The PBT precursor was a commercial Crastin ${ }^{\circledR}$ grade from DuPont in pellet form (Material reference: CRASTIN FGS600F40, Melting temperature $225^{\circ} \mathrm{C}$, Glass transition temperature $55^{\circ} \mathrm{C}$, dried $24 \mathrm{~h}$ at $160^{\circ} \mathrm{C}$ before injection). As diepoxide, we used the commercial bisphenol-A epichlorhydrin resin DER332, (Olin epoxy) with an $[\mathrm{OH}]$ /epoxy ratio lower than 0.02 , further on referred as diglycidyl ether of bisphenol A (DGEBA). We produced three different polymers: Pristine PBT and two vitrimers denoted $V_{1}$ and $V_{2}$. The subscript indicates the weight percentage of crosslinking agent (DGEBA). The detail of the prepared blends is presented in table 1. 


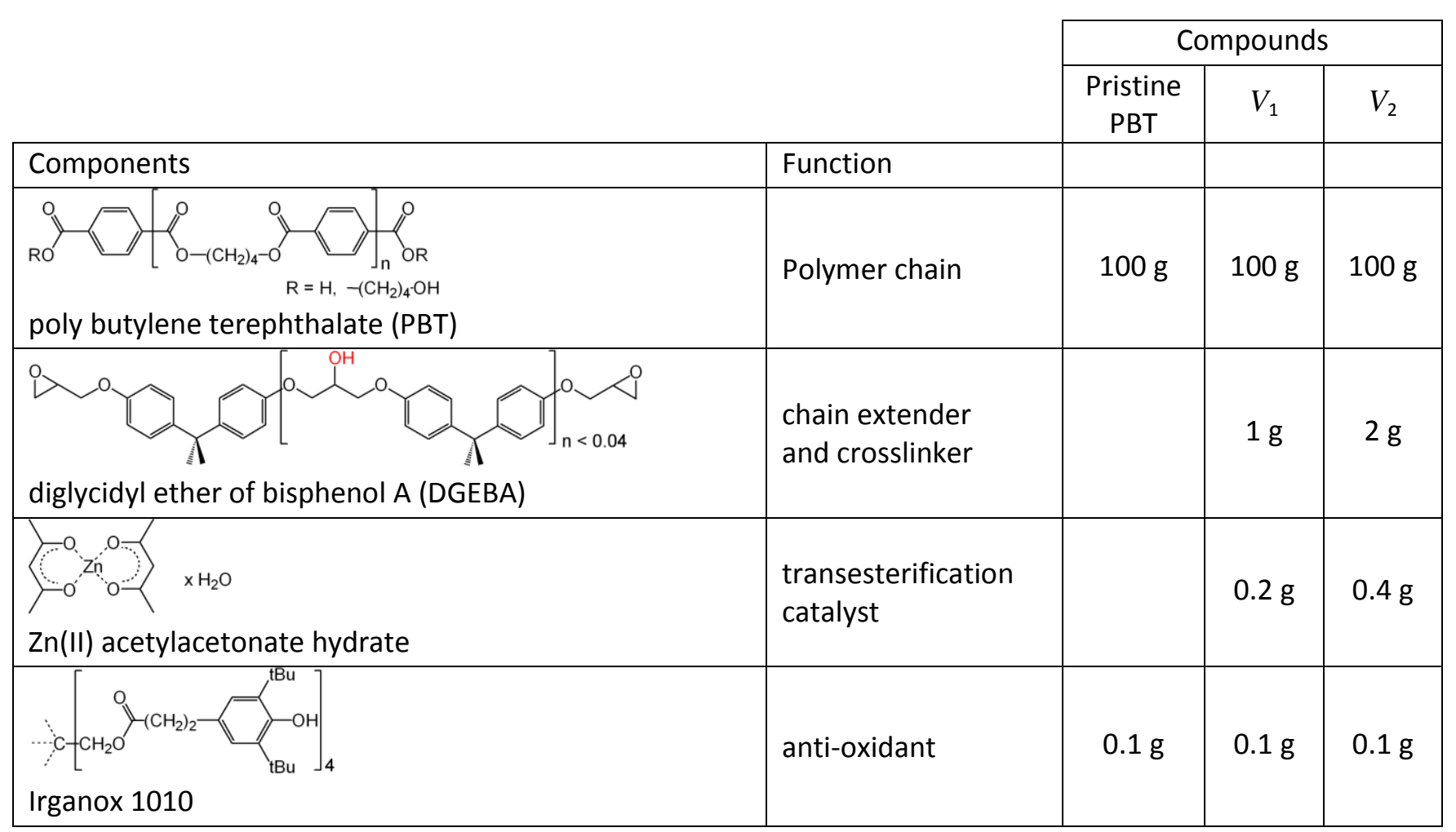

Table 1 Prepared blends

We introduced the mixture in a $12 \mathrm{~cm}^{3}$ DSM Xplore twin-screw micro-compounder under a nitrogen flux. The micro-compounder was equipped with a recirculation channel to control the residence time. We set the temperature and the rotor speed to $270^{\circ} \mathrm{C}$ and $100 \mathrm{rpm}$ respectively. We also recorded the axial force exercised on the barrel of the compounder in order to monitor the melt viscosity changes. For $V_{1} \quad$ (1\% DGEBA) and $V_{2} \quad$ (2\% DGEBA), the force signal increased up to 5000 and $7000 \mathrm{~N}$ respectively while remaining lower than $2000 \mathrm{~N}$ for the pristine PBT. This proves that crosslinking actually did occur when the diepoxide and the catalyst were incorporated in the mixture. When the force reached its maximum value after about 5 minutes, we transferred the melt to a shooting pot and injected it into a tensile specimen shape mould at $200^{\circ} \mathrm{C}$ (figure $1 \mathrm{c}$ ). The polymer was next cured for 4 minutes before we removed the specimen from the mould. The volume of the microcompounder means that only one tensile specimen can be obtained at a time (see figure $1 \mathrm{~b}$ for the specimen dimensions) and the production of this unique specimen takes approximately half an hour.

Unlike the pristine PBT which is white, the two vitrimers each have a pale brown colour which is more pronounced for $V_{2}$. 


\subsection{Mechanical testing}

We studied the solid rheological properties of the polymers produced by performing tensile tests using a Bose ${ }^{\circledR}$ 3000 machine equipped with a thermal chamber and a $3 \mathrm{kN}$ load cell (see figure 1a). The tensile force is denoted $F$. The relative speed displacement of the tensile machine grips was $0.02 \mathrm{~ms}^{-1}$. The maximum displacement of the grips is $18 \mathrm{~mm}$. Dog-Bone shaped specimens were designed with a $6 \mathrm{~mm}$ long central cubic part to control the localization and development of plastic instability exactly in the middle of specimens (figure $1 \mathrm{~b}$ ). In the absence of strain localization (necking), the strain in the specimen central part remains approximately constant.

We measured the strain on the specimen surface using an Aramis 3 D Digital Image Correlation (3D DIC) device provided by the Gom ${ }^{\circledast}$ company (see the cameras in figure 1a). To achieve image correlation, a random black speckle pattern was applied on the specimen surface with a paint airbrush. The measurement was performed through a glass window placed on the front door of the temperature chamber. The longitudinal strain is expressed in terms of logarithmic or true strain (see section 1 of the Supporting Information for more details): $\varepsilon=\ln \left(\frac{l}{l_{0}}\right) \cdot l_{0}$ is a small length element taken on the undeformed specimen along the $x$ tensile axis and $l$ is its current size during deformation. The strain in the specimen central cross-section is denoted $\varepsilon^{M}$. As previously mentioned, $\varepsilon^{M}$ is the maximum strain along the specimen length. The true (or Cauchy) stress is defined as $\sigma=\frac{F}{S} . S$ is the current area of the specimen central cross-section. Working with the assumption of an isochoric deformation process, the true stress in the specimen central section can be shown to be given by (see section 1 of the Supporting Information): $\sigma=\frac{F}{S}=\frac{F}{S_{0}} e^{\varepsilon^{M}} . S_{0}=6 \times 6=36 \mathrm{~mm}^{2}$ is the initial area of the central cross-section. The nominal stress (or engineering stress) is given by $\sigma_{N}=\frac{F}{S_{0}}=\sigma e^{-\varepsilon^{M}}$.

We performed the tensile tests at temperatures between the glass transition $\left(T_{g} \approx 50^{\circ} \mathrm{C}\right)$ and the melting point ( $T_{m} \approx 225^{\circ} C$, see section 2 of the SI). For a pristine PBT, the former condition is well known to insure that a plastic flow will occur and that the material will not exhibit brittle behaviour. 

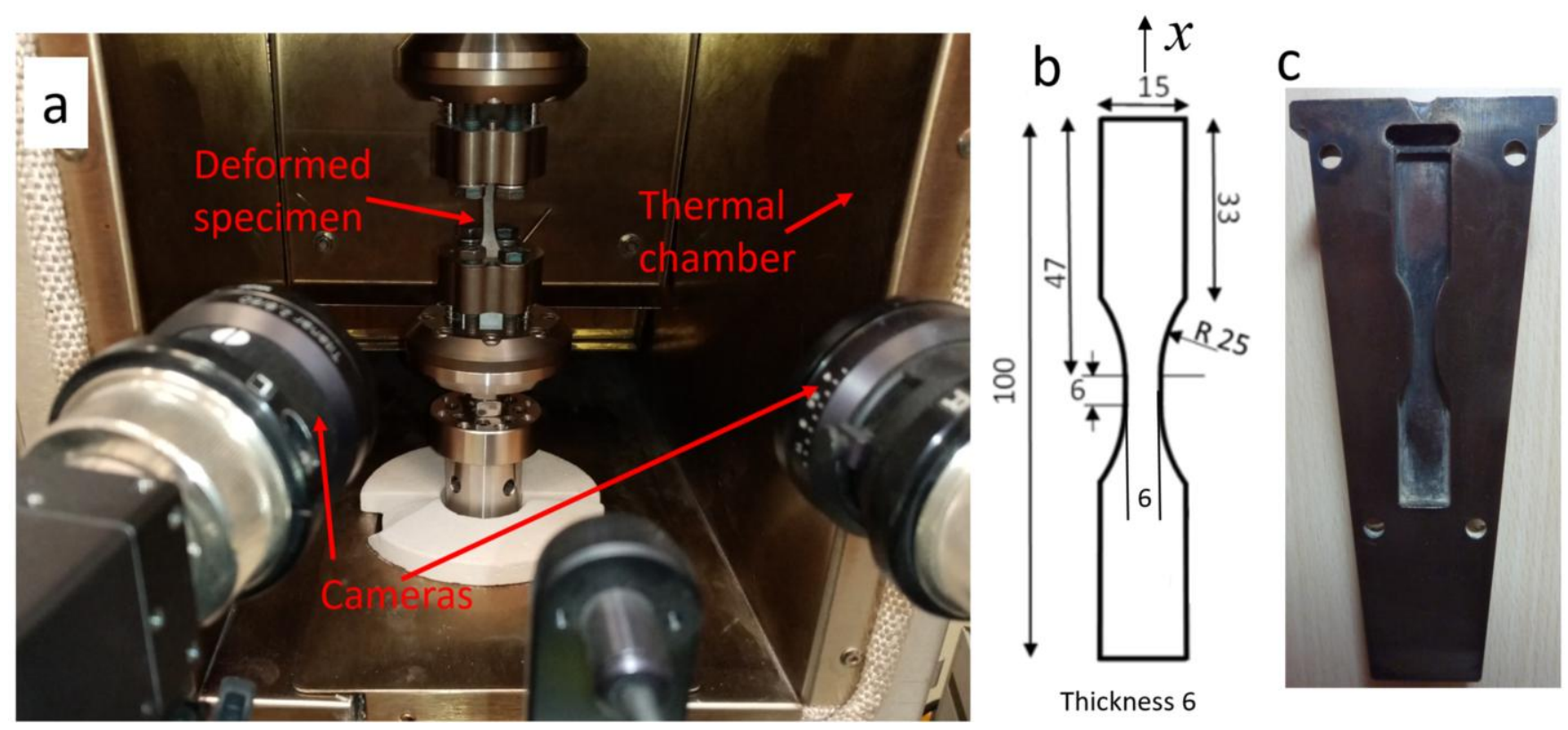

Figure 1 Experimental set-up a) Photography showing the specimen in the tensile machine grips and the 3D DIC cameras (the oven front door is removed), b) Dimensions of the undeformed specimen, c) Specimen mould.

\subsection{Rheometry}

Dynamic shear measurements were carried out on a strain- controlled ARES G2 rheometer from TA Instruments at $270^{\circ} \mathrm{C}$ under a nitrogen flux. Parallel plate geometry was used. The pulsation was set to $\omega=1 \mathrm{rad} / \mathrm{s}$ ( $f=0.16 \mathrm{~Hz})$ and the imposed strain to $0.5 \%$.

\subsection{Thermal analysis}

The details about the experiments of Differential Scanning Calorimetry (DSC) and ThermoGravimetric Analysis (TGA) are given in section 2 and 3 of the SI.

\subsection{X ray-diffraction}

The description of the $\mathrm{X}$ ray-diffraction measurement is given in section 4 of the SI. 


\section{Solid rheology of PBT-based vitrimers}

\subsection{The semi-crystalline structure of solid PBT-based vitrimers}

Crosslinking PBT using epoxy vitrimer chemistry in batch extrusion has already been described by Demongeot et al. ${ }^{13}$ The reagents are depicted in Table 1 . In short, the reactive functions (either $-\mathrm{OH}$ or $\mathrm{COOH}$ ) present at the chain ends of PBT react with the epoxy functions of DGEBA, leading to the creation of resp. hydroxy ether and hydroxy ester links. The result of these addition reactions is a chain extension of PBT and the appearance of lateral hydroxide groups (in red in scheme 1), in addition to those already present (in minute amounts) in DGEBA (in red in Table 1).

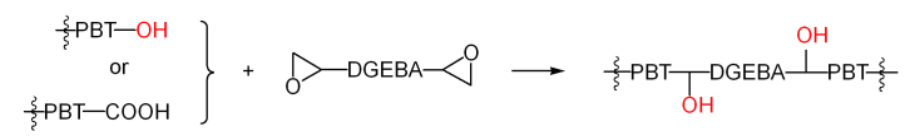

Scheme 1

Then, the $\mathrm{Zn}(\mathrm{II})$ transesterification catalyst comes into action and promotes crosslinking through exchange reactions between main chain ester links and the newly formed hydroxide groups (scheme 2). At temperatures above $230^{\circ} \mathrm{C}$, chain extension and crosslinking occur within a few minutes.

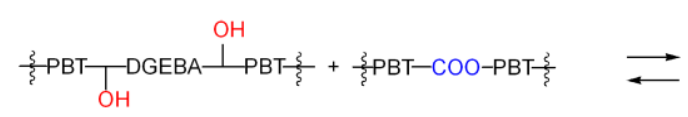

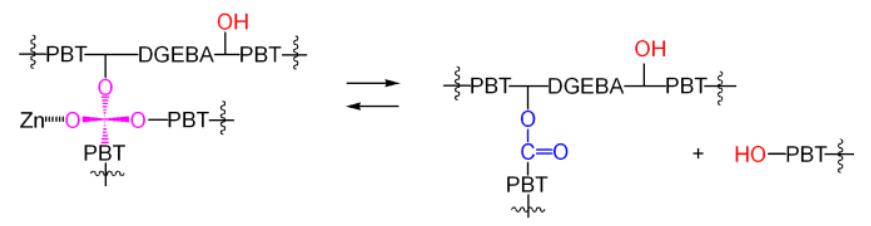

Scheme 2

Following this, the exchanges by transesterification continue, provided that they are thermally activated. The important feature, related to the characteristic associative behavior of crosslinking in vitrimers, is that new bonds form before existing ones are broken, thus allowing malleability at high temperature while maintaining connectivity at any time. 
After extrusion, Demongeot et al. checked that the material was insoluble but remained heat processable and thereby showed the characteristic features of a vitrimer. ${ }^{13}$ Crystallization was preserved (and even accelerated) in the vitrimer and the overall degree of crystallinity slightly decreased according to the amount of crosslinker.

According to the manufacturer, ${ }^{44}$ here, the starting PBT has a density of $\rho_{p}=1.310 \mathrm{~g} / \mathrm{cm}^{3}$, intermediate between that of the amorphous $\left(\rho_{a}=1.265\right.$ to $\left.1.268 \mathrm{~g} / \mathrm{cm}^{3}\right)$ and that of the $\alpha$ crystalline form $\left(\rho_{c}=1.403 \mathrm{~g} / \mathrm{cm}^{3}\right)^{43}$. Based on density values, the volume fraction of crystal is equal to:

$\phi_{c}=\left(\frac{1}{\rho_{a}}-\frac{1}{\rho_{p}}\right) /\left(\frac{1}{\rho_{a}}-\frac{1}{\rho_{c}}\right)=34 \%$

On the diffraction spectrum of unstretched injected tensile bars of PBT and $V_{2}$ (figures S2 and S3), the spectrum of the $\alpha$ form superimposed on an amorphous signal can be recognized. The integration of the Bragg peaks between 0.4 and $2.4 \AA^{-1}$ compared to the area of the amorphous signal in I $(q)$ representation gives a ratio of 0.43 for $V_{2}$ against 0.52 for the PBT, showing that despite a decrease in crystallinity of about $15 \%$ the structure remains the same after vitrimerization. The measurements by DSC on injected specimens confirm that the crystallinity is present in all cases and that the degree of crystallinity goes from approximately $34 \%$ for the PBT to $32 \%$ for $V_{1}$ and $30 \%$ for $V_{2}$ (see table S1). Concerning the TGA results (see figure S1), they are basically the same for PBT and the vitrimers, showing a single degradation step between 350 and $400{ }^{\circ} \mathrm{C}$. Vitrimers only differ by a slightly higher char residue, consistent with their crosslinked structure. ${ }^{45}$

As PBT is a hardly entangled polymer, exhibiting very little melt viscosity, its rheological properties in the solid phase between $T_{g}$ and $T_{m}$ are mainly governed by crystallinity. In this temperature range, the cohesion of the uncross-linked PBT is therefore ensured by the presence of tie chains uniting the crystalline lamellae to each other and of entangled loops which add physical nodes (figure 2a). In this context, vitrimerization brings about two things - firstly chemical cross-linking of the tie chains (figure $2 \mathrm{~b}$ ) which increases the cohesion and secondly the possibility of relaxing stresses by rearrangement of the chemical bonds (figure 2c). As these two effects go in opposite directions, the net result on solid phase properties such as tensile strength or creep resistance is not easy to predict. 


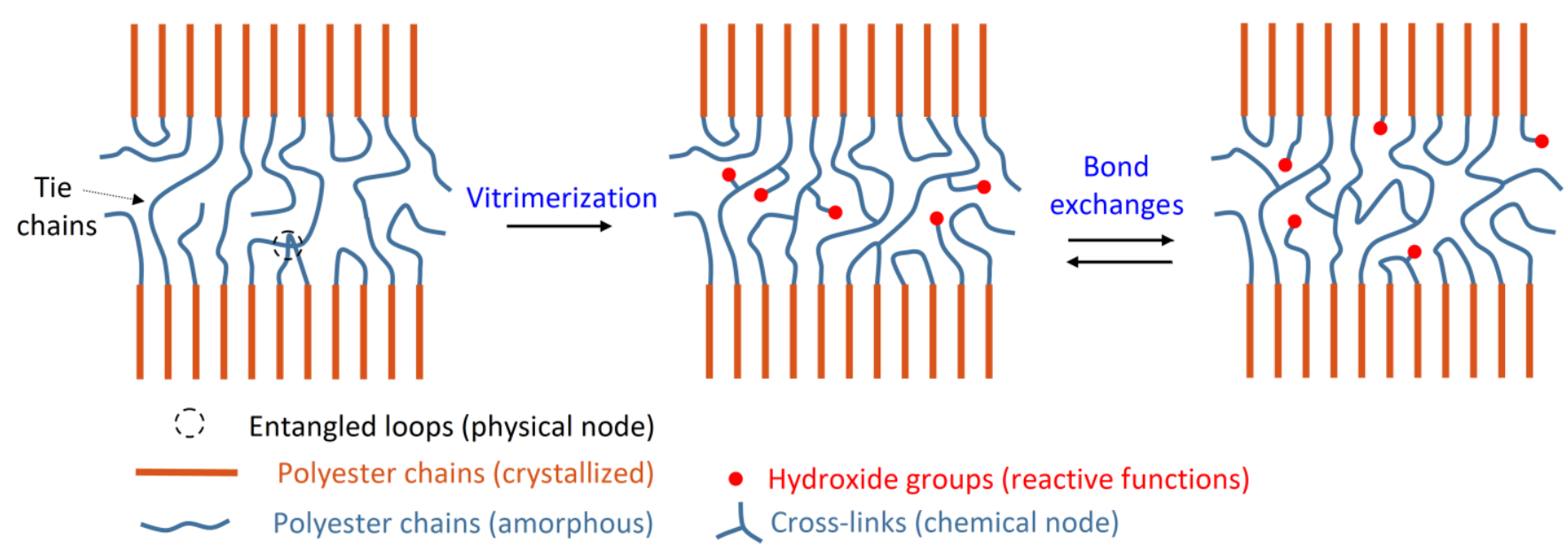

Figure 2 Schematic representation of the crystalline and amorphous parts of a neat SCP polymer a) and of a SCPbased vitrimer $b-c)$.

\subsection{Plastic strain localization and strain hardening}

The strain profiles $\varepsilon(x)$ along the specimen length ( $x$-axis) are represented in figure 3 for the pristine PBT as well as for the $V_{1}$ and $V_{2}$ vitrimers. These three curves were measured when the maximum strain in the central cross-section was the same: $\varepsilon^{M}=0.4$. The experiments were performed at $T=160^{\circ} \mathrm{C}$, which practically corresponds to the maximum temperature at which unreinforced PBT retains good mechanical properties. We made two distinct tests for each material to check repeatability. 


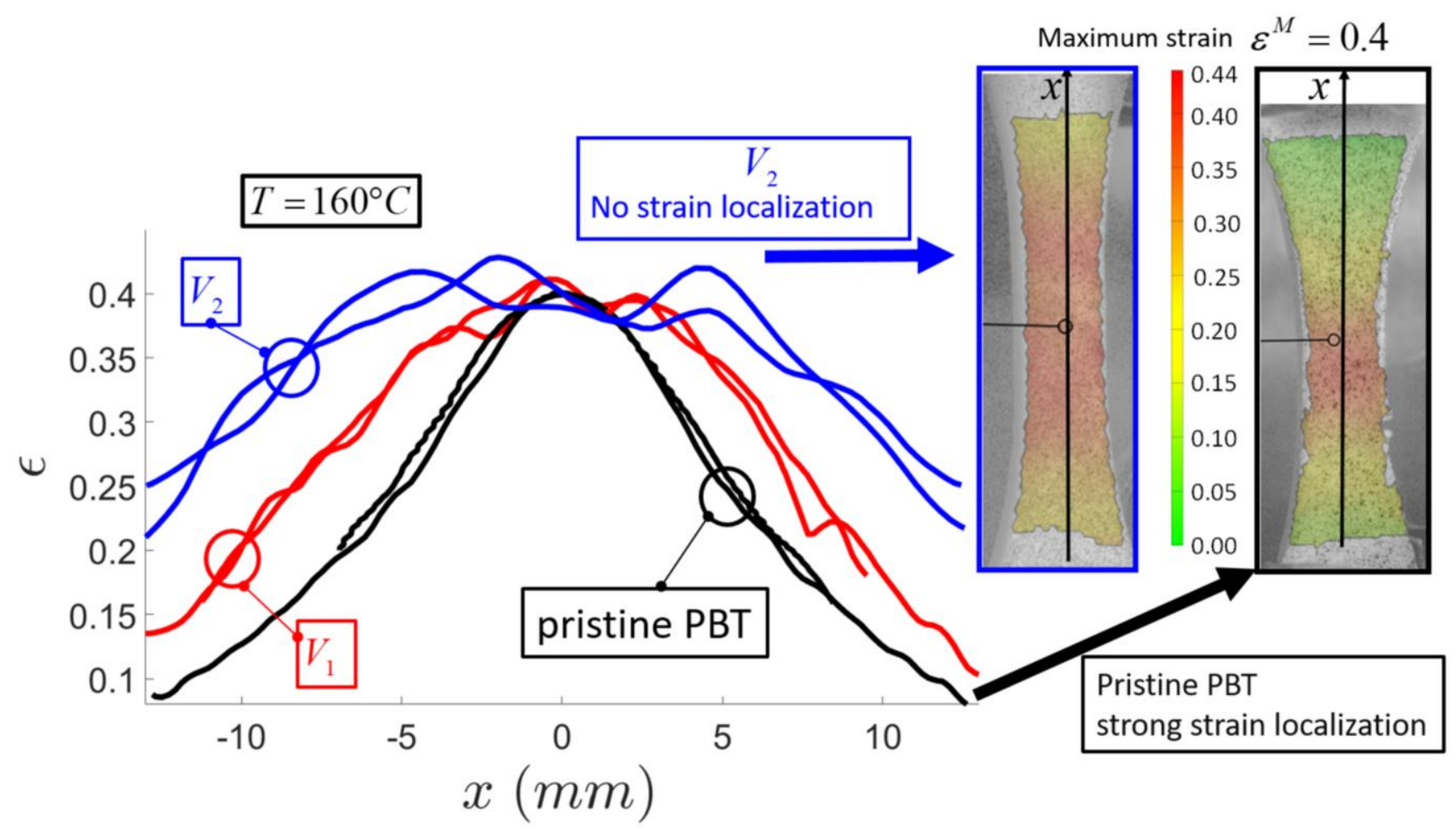

Figure 3 Strain profiles measured along the specimen central axis ( $x$-axis) at $T=160^{\circ} C$ for the pristine PBT and the $V_{1}$ and $V_{2}$ vitrimers. The strain in the specimen centre is the same for the three curves $\left(\varepsilon^{M}=0.4\right)$. Note that the colour scale of the pristine PBT (right) and $V_{2}$ (left) strain maps is the same.

The pristine PBT curve displays a marked maximum in the specimen centre. This corresponds to the strain localization phenomenon (necking) that is generally observed during tensile deformation of SCPs at temperatures between $T_{g}$ and $T_{m} \cdot{ }^{46}$ Conversely, in the case of $V_{2}$, the strain is nearly constant along the specimen length. Plasticity is associated there with a uniform development of the strain over the entire specimen. The slight strain decrease that can be observed from either side of the curves can be attributed to the initial geometry of our dogbone specimen (see figure 1b). The $V_{2}$ strain profile appears noisy. This is due to the lack of contrast between the random black pattern and the brown surface of the $V_{2}$ vitrimer. The difference in behaviour between $V_{2}$ and the pristine PBT is effectively illustrated by the specimen photography and by the strain fields obtained when the strain in the specimen centre was $\varepsilon^{M}=0.4$ (see the insert in the figure 3 right part). In the case of the $V_{2}$ vitrimer, because the strain is uniform and nearly equal to the maximum value $\varepsilon^{M}=0.4$, the total length of the specimen (and therefore the relative displacement of the tensile machine grips) is much longer than that of the 
pristine PBT specimen. This means that the maximum strain corresponding to a given displacement of the grips differs greatly between the pristine PBT and $V_{2}$.

The strain localization phenomenon can also be observed for the $V_{1}$ vitrimer (Figure 3 ) but it is much less pronounced than for the pristine PBT. This shows that this material has intermediate behaviour between that of the pristine PBT (strong strain localization) and $V_{2}$ (quasi-uniform deformation). Compared to $V_{2}$, the noise is reduced for the 3 D DIC measurements that were performed on the $V_{1}$ specimen. As previously mentioned, the colour of the $V_{1}$ specimen is lighter and the contrast with the black speckle pattern is better.

Figure 4 shows the force variations as a function of $\varepsilon^{M}$ for $V_{1}, V_{2}$ and the pristine PBT. Analysis of the force signals confirmed the findings deduced from the strain fields shown in Figure 3 . The curves corresponding to the pristine PBT have a characteristic shape, exhibiting a load maximum, i.e. a yield point, for $\varepsilon^{M} \approx 0.25$. The yield point is well-known to be associated with the development of necking. On the other hand, the force signal for the $V_{2}$ vitrimer exhibits no yield point and the curve slope remains clearly positive throughout the test. This confirms that the plastic deformation process occurs in a uniform way, i.e. without any strain localization effect. The curves corresponding to the $V_{1}$ vitrimer also show no yield point. However, enlarging the curve (see the insert in right upper part of figure 4) reveals that the curve seems very close to reaching a maximum value but instead of that, passes through an inflexion point and resumes to increase. At $160^{\circ} \mathrm{C}$, rupture was never observed for both $V_{1}$ and $V_{2}$ as well as for the pristine PBT. The test was stopped when the tensile machine maximum displacement was reached. 


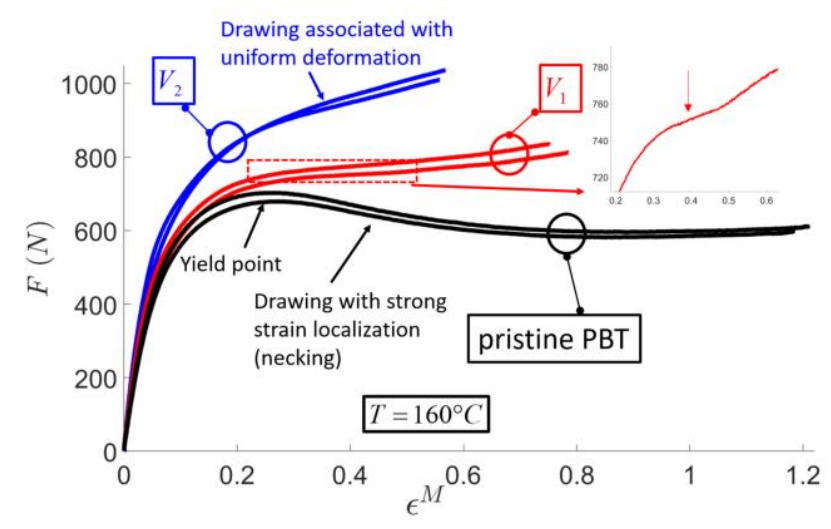

Figure 4 Evolution of the force signal $(F)$ at $T=160^{\circ} \mathrm{C}$ for the pristine PBT and the $V_{1}$ and $V_{2}$ vitrimers. Two distinct tests are shown for each material. The tests were stopped when the maximum displacement of the tensile machine grips was reached. At the end of the test, the maximum strain $\left(\varepsilon^{M}\right)$ depends on the strain localization degree and differs for the three materials.

In order to analyse the difference in behaviour between the three materials further, we also plotted the curves, intrinsic to each material, which relate the true stress $\sigma$ to the true stain $\varepsilon^{M}$ both measured in the central crosssection of the specimen (figure 5).

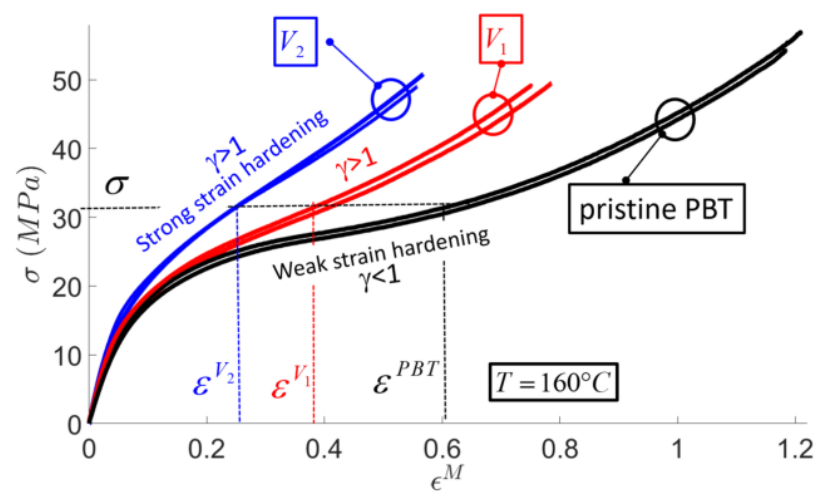

Figure 5 True stress $(\sigma)$ against true strain $\left(\varepsilon^{M}\right)$ curves for the pristine PBT and the $V_{1}$ and $V_{2}$ vitrimers. $T=160^{\circ} \mathrm{C}$. 
In the case of PBT, the true stress $\left(\sigma=\frac{F}{S}\right)$, actually undergone by the material, increases continuously with $\varepsilon_{M}$ whereas the nominal or engineering stress $\left(\sigma_{N}=\frac{F}{S_{0}}\right)$ shows a maximum and a decreasing part (see figure 4). From the $\sigma\left(\varepsilon_{M}\right)$ curves, it is easy to obtain the evolution of the strain-hardening coefficient defined as $\gamma\left(\varepsilon_{M}\right)=\frac{d \ln (\sigma)}{d \varepsilon_{M}}$ (figure 6). This quantity makes it possible to establish a link between the possible occurring of necking observable at the specimen scale, and the material's intrinsic properties. Assuming there is an isochoric deformation process, a simple calculation (section 1 of the $\mathrm{SI}$ ) shows that the force curve is only likely to exhibit a maximum (yield point) if the intrinsic quantity $\gamma$ becomes smaller than $1 .{ }^{46,47}$ Figure 6 confirms that $\gamma$ remains larger than 1 throughout the deformation process for the $V_{1}$ and $V_{2}$ vitrimers for tests performed at $T=160^{\circ} \mathrm{C}$. For the pristine PBT, $\gamma$ becomes smaller than 1 at the yield point. Next, for $\varepsilon^{M} \approx 0.9, \gamma$ again becomes larger than 1 which corresponds to neck stabilization. ${ }^{47-49}$

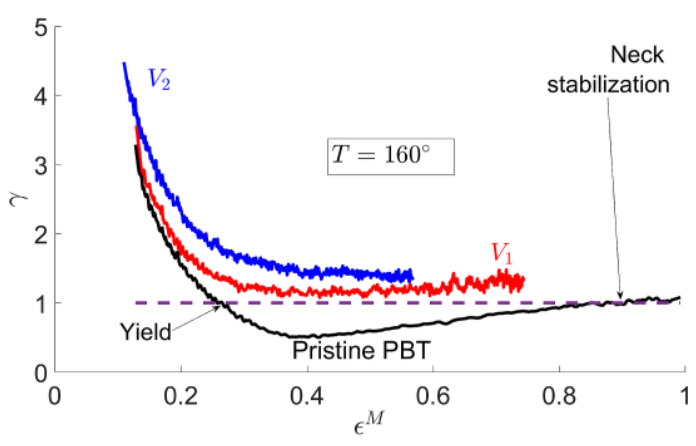

Figure 6 Evolution of the strain-hardening coefficient $\gamma=\frac{d \ln (\sigma)}{d \varepsilon^{M}}$ at $T=160^{\circ} C$. Necking occurs if $\gamma$ becomes smaller than 1.

In figure 5, the first part of the curves roughly corresponds to the elastic behaviour and subsequently the mechanical properties of the vitrimers and pristine PBT are strongly different. The $V_{2}$ vitrimer clearly shows better resistance to deformation than the pristine PBT: at a given $\sigma$ level, the strain is much smaller for $V_{2}$ than for PBT $\left(\varepsilon^{V_{2}}<\varepsilon^{P B T}\right.$ in figure 5). Again the behaviour of $V_{1}$ is intermediate when compared to the pristine PBT 
and $V_{2}\left(\varepsilon^{V_{2}}<\varepsilon^{V_{2}}<\varepsilon^{P B T}\right)$. This confirms that the vitrimer's solid mechanical properties can be tuned using the concentration of the crosslinking agent DGEBA.

At the microstructure level, the strain hardening of SCPs has been proven to mainly depend on chain entanglement density. ${ }^{50-53}$ Logically, the higher the entanglement density, the less extensible the macromolecular network and at macro-level this results in strain hardening enhancement. In addition to the "physical nodes" associated with the entanglements, a SCP vitrimer includes "chemical nodes" created during material crosslinking (see figure 2). In the case of the vitrimer, the semi-crystalline morphology is preserved; the additional presence of "chemical nodes" means the distance between the nodes is smaller and the macromolecular network of the SCPbased vitrimer is less extensible than that of its pristine SCP precursor. Consequently, strain hardening increases and necking may be suppressed.

This interpretation to explain necking suppression does not take into account the dynamic character of the vitrimer covalent networks. Temperature of $160^{\circ} \mathrm{C}$ is both well above $T_{g} \approx 50^{\circ} \mathrm{C}$ and well below $T_{m} \approx 225^{\circ} \mathrm{C}$. At $T=150^{\circ} \mathrm{C}$, studies of $\mathrm{Zn}(\mathrm{II})$ catalyzed transesterification on model molecules ${ }^{54}$ with a $[\mathrm{Zn}] /[\mathrm{OH}]$ ratio of $5 \%$ give an exchange half time of about $10 \mathrm{~min}$ and complete equilibration after about $1 \mathrm{~h}$ whereas stress relaxation data of an amorphous systems in the rubbery state give relaxation times of about $10^{4} \mathrm{~s}^{1}$ Here, temperature (160 ${ }^{\circ} \mathrm{C}$ ) and the $\mathrm{Zn}$ molar concentration (about $12 \mathrm{~mol} \%$ ) are both a little higher, therefore chemical exchanges cannot be excluded, within the time scale of a tensile experiment (about 900s). However, we can see that on this time scale, the situation does not look at all like in the absence of cross-links. It therefore appears that although exchanges can take place, the permanence of the network associated with a high degree of crystallization in the semi-crystalline vitrimer gives the material sufficient connectivity to overcome the low degree of entanglement of the PBT.

Few examples of necking suppression in SCPs related to network properties have been reported in the literature. Unwin et al. found that a branched polyethylene exhibits no necking if the tensile force is applied along the material extrusion direction. ${ }^{55}$ This was attributed to a residual anisotropy of the macromolecular network remaining after the extrusion process. Although this is not discussed in the article, the results obtained by 
Khonakdar et al. (see figure 7 of the cited article) show that necking can be suppressed for HDPE by chemically crosslinking the polymer with a peroxide agent. ${ }^{56}$

\subsection{Temperature dependency of vitrimers' mechanical properties}

The evolution of the tensile force $F$ at $80^{\circ} \mathrm{C}, 120^{\circ} \mathrm{C}$ and $160^{\circ} \mathrm{C}$ is represented in figure 7 for the $V_{1}$ vitrimer. As expected, the higher the temperature, the lower the force as is the case for all polymer materials. At $80^{\circ} \mathrm{C}$, a maximum is again observable on the curve, which suggests that the strain localization phenomenon is accentuated when the temperature decreases. This can also be seen in the evolution of the strain-hardening coefficient which becomes smaller than 1 during the deformation process (see figure S4). Analysis of the strain profiles measured at $\varepsilon^{M}=0.4$ (figure 8 ) confirmed this assumption - the smaller the temperature the narrower the strain peaks. The evolution of the tensile force $F$ for $V_{2}$ and the pristine PBT are shown at $80^{\circ} \mathrm{C}, 120^{\circ} \mathrm{C}$ and $160^{\circ} \mathrm{C}$ in the supporting information (figure $\mathrm{S} 6$ and figure $\mathrm{S7}$ ). Both for $V_{1}$ and $V_{2}$, no yield point can be seen on the force signals at $120^{\circ} \mathrm{C}$. The pristine $\mathrm{PBT}$ is similar to $V_{1}$ in that the higher the temperature the narrower the strain peaks measured at $\varepsilon^{M}=0.4$ (figure S8). For the $V_{2}$ vitrimer, at $120^{\circ} \mathrm{C}$ the strain profile looks like a broad hump which is slightly narrower than that obtained at $160^{\circ} \mathrm{C}$ (figure S9).

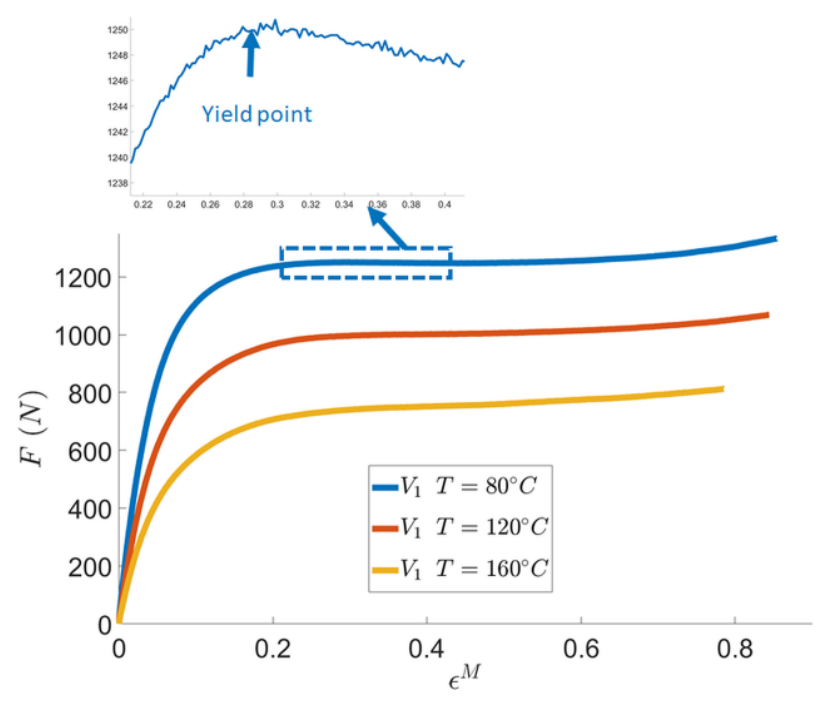

Figure 7 Evolution of the force signal during the test for the $V_{1}$ vitrimer at $80^{\circ} \mathrm{C}, 120^{\circ} \mathrm{C}$ and $160^{\circ} \mathrm{C}$. 


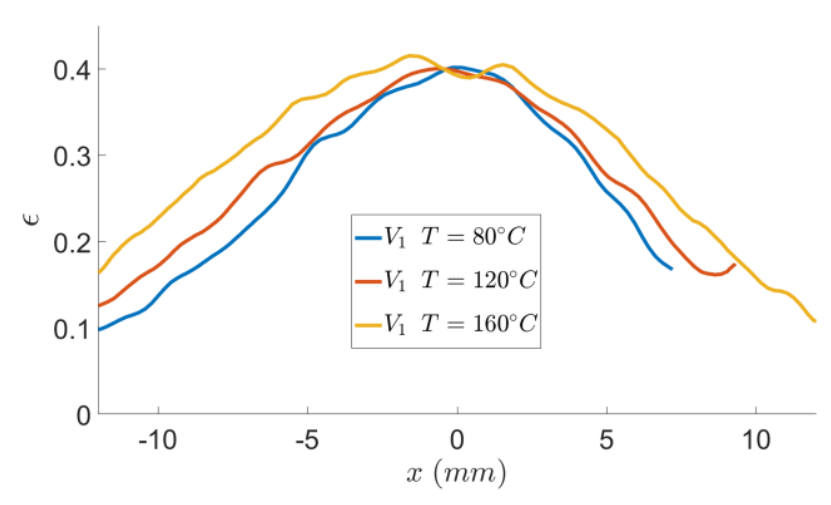

Figure 8 Strain profiles at $80^{\circ} \mathrm{C}, 120^{\circ} \mathrm{C}$ and $160^{\circ} \mathrm{C}$ taken along the specimen length $\left(x\right.$-axis) for the $V_{1}$ vitrimer. The measurement is made when the strain is the same in the specimen centre $\left(\varepsilon^{M}=0.4\right)$.

Figure 9 shows the true strain-true stress curves obtained for the three studied materials at $80^{\circ} \mathrm{C}$ (figure 9 a) and $120^{\circ} \mathrm{C}$ (figure $9 \mathrm{~b}$ ). At $120^{\circ} \mathrm{C}$ as at $160^{\circ} \mathrm{C}$, we can see that the $V_{2}$ vitrimer shows the best resistance to deformation and also that the $V_{1}$ vitrimer's resistance to deformation is better than that of the pristine PBT.

For the vitrimer with the highest DGEBA concentration $\left(V_{2}\right)$, rupture was observed before the end of the tensile test for strain levels corresponding to $\varepsilon^{M}=0.15$ (or engineering strain $16 \%$ ) at $80^{\circ} C$ and $\varepsilon^{M}=0.61$ (or engineering strain $84 \%)$ at $120^{\circ} \mathrm{C}$. The Reduction of elongation at break is a well-known characteristic of crosslinked materials. ${ }^{57}$ Recent studies have confirmed the increase in brittleness with the crosslinking degree for solid vitrimers (PE-based vitrimers ${ }^{26,27,39}$ and polydimethylsiloxane-based vitrimers ${ }^{17}$ ). Furthermore, the PBT elongation at break has already been observed to sometimes strongly decrease with temperature in a $50^{\circ} \mathrm{C}$ temperature interval above $T_{G}{ }^{58}$ This could provide an insight as to why the elongation at break of $V_{2}$ is much smaller at $80^{\circ} \mathrm{C}$ than at $120^{\circ} \mathrm{C}$. Rupture was not observed for the $V_{1}$ vitrimer or for the pristine PBT. 

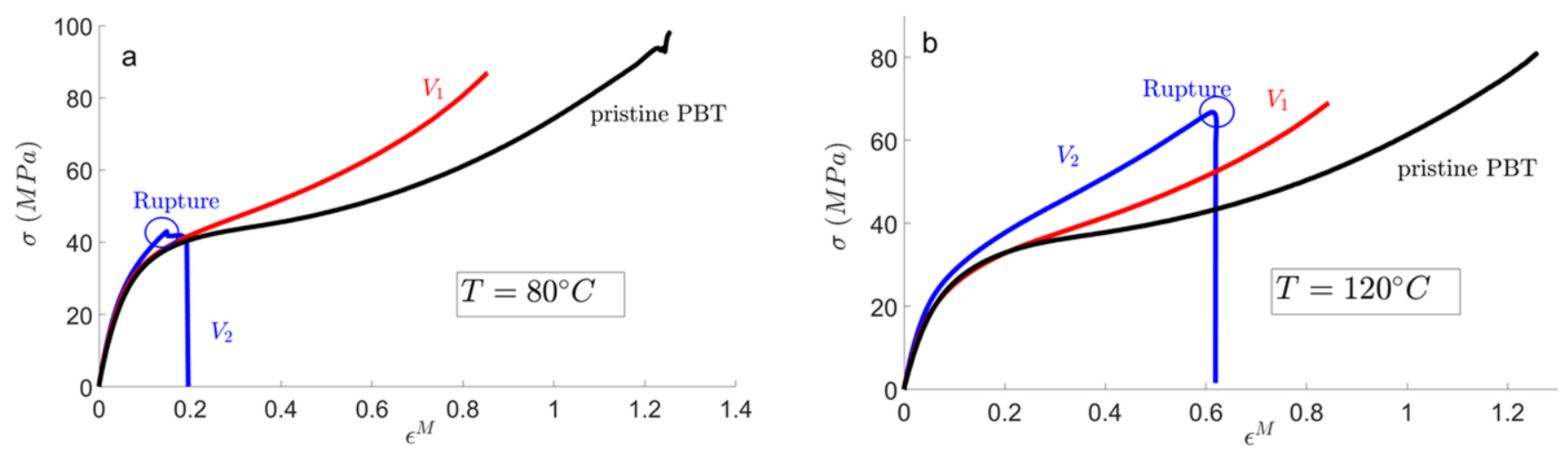

figure 9 True stress $(\sigma)$ against the maximum strain $\left(\varepsilon^{M}\right)$ curves for the pristine PBT and the $V_{1}$ and $V_{2}$ vitrimers at a) $80^{\circ} \mathrm{C}$ and b) $120^{\circ} \mathrm{C}$.

The mechanical properties of the pristine PBT as well as those of $V_{1}$ and $V_{2}$ at $80^{\circ} \mathrm{C}, 120^{\circ} \mathrm{C}$ and $160^{\circ}$ are summarized in Table 2. The Young modulus values (Table 2, last line) are in accordance with our previous comments regarding the materials' rigidities: at a given temperature, $E^{V_{2}}>E^{V_{1}}>E^{P B T}$.

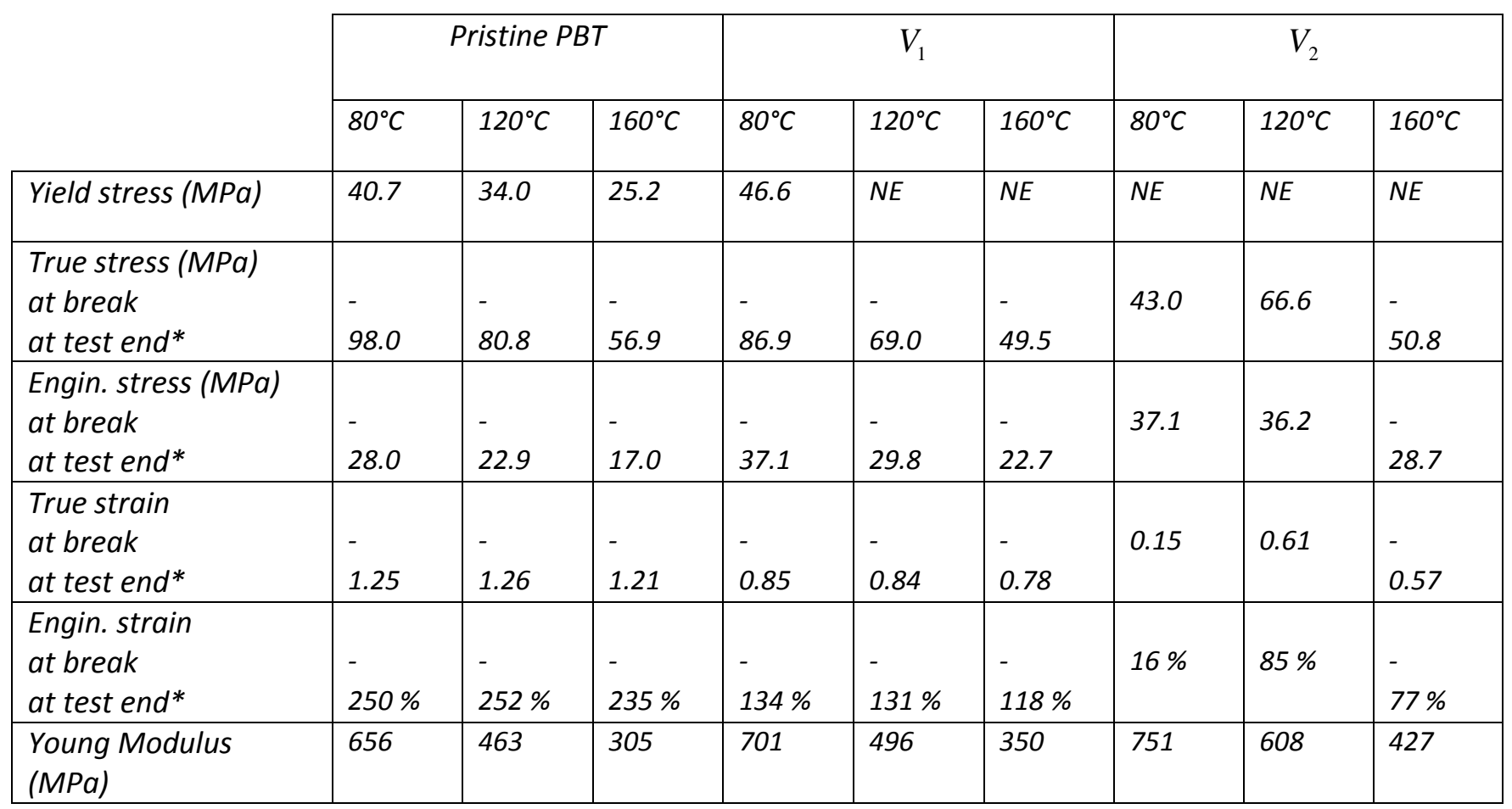

Table 2 Mechanical properties of the pristine PBT as well as of the $V_{1}$ and $V_{2}$ vitrimers. ${ }^{*}$ Test ends at $18 \mathrm{~mm}$ grip displacement when the sample is not broken. NE: Non-Existing.(-): Not available. 


\subsection{Creep and dimensional stability}

To estimate the potential benefits of vitrimers in terms of dimensional stability, creep experiments were carried out at $T=160^{\circ} \mathrm{C}$ for constant nominal stresses of $\sigma_{N}=10 \mathrm{MPa}(F=360 \mathrm{~N}$, figure 10a) and $\sigma_{N}=17.8 \mathrm{MPa}(F=640 \mathrm{~N}$, figure $10 \mathrm{~b})$. These experiments were performed with the same experimental setup as that shown in figure 1. A constant nominal stress was applied for 3600 s and the strain in the specimen centre $\varepsilon^{M}$ was measured through 3D DIC. Necking was never observed during the creep experiments and the strain can be considered as constant in the specimen $6 \mathrm{~mm}$ long central part (see figure $1 \mathrm{~b}$ ). Three creep characteristics are indicated in table 3: the instantaneous strain $\varepsilon^{M}\left(0^{+}\right)$, the final strain $\varepsilon^{M}(3600 s)$ and the average creep rate (denoted $C R$ ) measured in the $[1000-3600] s$ interval. The instantaneous strain $\varepsilon^{M}\left(0^{+}\right)$ was found to be significantly smaller for the vitrimers than for the pristine PBT. This confirms that the materials' rigidity is increased during the vitrimerization process. During test corresponding to $\sigma_{N}=10 \mathrm{MPa}$ (figure 10a), the true stress $\sigma=\sigma_{N} \exp \left(\varepsilon^{M}\right)$ imposed on the three materials remained nearly equal (difference smaller than $1.2 \%)$.

The creep rate measurement is illustrated in the insert in the lower part of figure 10a. The pristine PBT's $C R$ was found to be respectively $33 \%$ and $40 \%$ larger than those of the $V_{1}$ and $V_{2}$ vitrimers. The total creep strain $\left(\varepsilon^{M}(3600 s)-\varepsilon^{M}\left(0^{+}\right)\right)$of the two vitrimers was 0.014 , which is close to that of the pristine PBT (0.016). The differences observed between the three curves of figure 10a increased weakly during the creep phase although the creep rates are indeed significantly different. The curve shifts are mainly due to the difference in instantaneous strain values $\left(\varepsilon^{M}\left(0^{+}\right)\right)$(see table 3$)$.

At the end of the tests shown in figure 10a, the increase in length of the specimen central part where the stresses and strains are approximately constant can be calculated from the values indicated in table 3 . It is $5.8 \%$ $(\exp (0.056))$ for the neat $\mathrm{PBT}$ and $4.5 \%(\exp (0.044))$ for the $V_{2}$ vitrimer. This proves that specimen dimensional stability is better for the vitrimer material. The improvement in dimensional stability becomes very 
significant when tests were carried out with the highest nominal stress level ( $\sigma_{N}=17.8 M P a$, figure $10 \mathrm{~b}$ ). In this case, for a one-hour duration test the increase in length of the specimen central part was $29 \%$ for the pristine PBT and only $10 \%$ for the $V_{2}$ vitrimer. After 4 hours (see Supporting Information, figure S10), the increase in length was $35 \%$ for the pristine PBT and $11 \%$ for the $V_{2}$ vitrimer. Overall, these results prove that the dimensional stability of a PBT-based vitrimer part can be greatly improved compared to that of a identical part made of the PBT precursor. This is largely because the vitrimer materials exhibit smaller instantaneous strains compared to the pristine PBT. The creep rates of the vitrimer materials were also found to be smaller than that of the pristine PBT about four times smaller in the case of the $V_{2}$ vitrimer for the test carried out at the highest nominal stress level. However, in the case of the curves of figure 10b, the three materials were subjected to significantly different true stresses during the test. It is difficult to estimate the extent to which the reduction of the vitrimer creep rates are really related to the intrinsic behaviour of these materials or whether this is simply because the true stresses are smaller for the vitrimers than for the pristine PBT. Answering this question would require creep tests to be carried out at constant true stress levels which is very challenging on the experimental level. However, this point is of little interest if we are to consider the real case of a polymer part in service subjected to a constant force which possibly results from an accidental overload. Nonetheless, it should be born in mind by researchers working on modelling material behaviour laws.
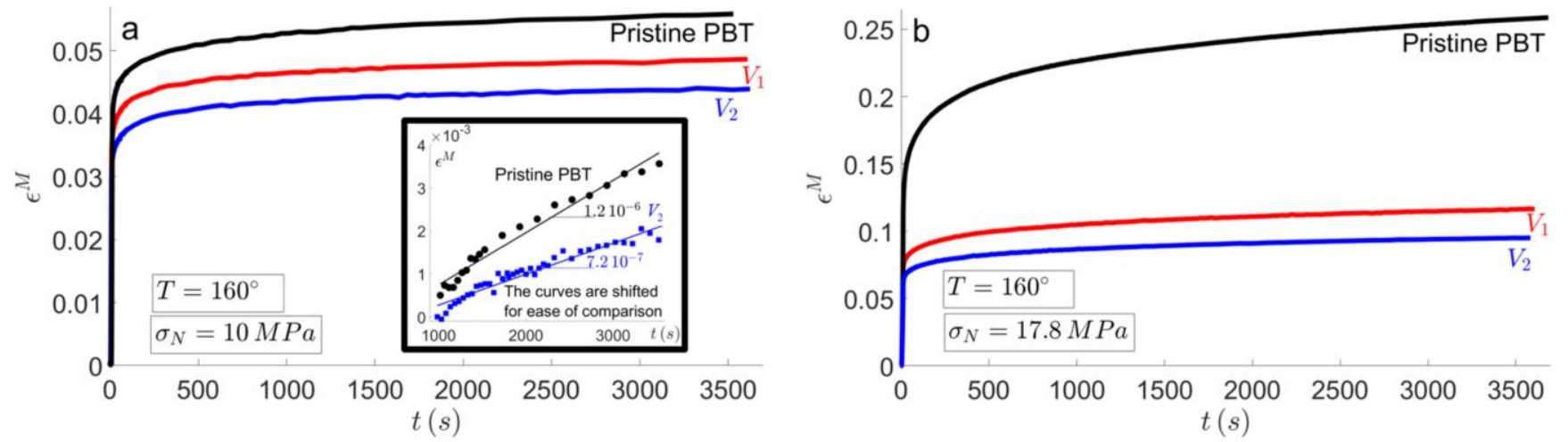

Figure 10 Creep experiments for $T=160^{\circ} \mathrm{C}, \sigma_{N}=10 \mathrm{MPa}$ a) and $\sigma_{N}=17.8 \mathrm{MPa}$ b). The creep rate $(\mathrm{CR})$ measurement for the pristine PBT and the $V_{2}$ vitrimer is illustrated in the insert placed in the low part of figure $10 a$. 


\begin{tabular}{|c|c|c|c|c|c|c|}
\cline { 2 - 7 } \multicolumn{1}{c|}{} & \multicolumn{3}{c|}{$\sigma_{N}=10 \mathrm{MPa}$} & \multicolumn{3}{c|}{$\sigma_{N}=17.8 \mathrm{MPa}$} \\
\cline { 2 - 7 } & $\begin{array}{c}\text { Pristine } \\
\text { PBT }\end{array}$ & $V_{1}$ & $V_{2}$ & $\begin{array}{c}\text { Pristine } \\
\text { PBT }\end{array}$ & $V_{1}$ & $V_{2}$ \\
\hline Instantaneous strain $\varepsilon^{M}\left(0^{+}\right)$ & 0.040 & 0.035 & 0.030 & 0.117 & 0.072 & 0.061 \\
\hline Final strain $\varepsilon^{M}(3600 s)$ & 0.056 & 0.049 & 0.044 & 0.258 & 0.117 & 0.095 \\
\hline $\begin{array}{c}\text { Average creep rate } C R \text { in the } \\
{[1000-3600] s \text { interval } s^{-1}}\end{array}$ & $1.210^{-6}$ & $8.110^{-7}$ & $7.210^{-7}$ & $1.2810^{-5}$ & $0.4310^{-5}$ & $0.3410^{-5}$ \\
\hline
\end{tabular}

Table 3. Pristine $P B T, V_{1}$ and $V_{2}$ creep characteristics.

The experiments reported in section 2 show that the plastic deformation mechanisms of vitrimers differ drastically from those of their pristine PBT precursor. Furthermore, our creep experiments clearly suggest the potential benefits of vitrimers in terms of dimensional stability. These promising results highlight the need for systematic and thorough studies of the mechanical properties of these new materials to be carried out. This kind of objective requires experiments to be run using several variable parameters namely DGEBA concentration, catalyst concentration, temperature and strain rate. In addition to monotonic tensile tests, a wide range of mechanical tests is required such as tensile tests including loading and unloading stages, fatigue tests, multi-axial tests, relaxation tests or creep tests at various constant stresses. Overall, this would also require a great amount of tensile specimens which cannot be produced using the non-continuous reactive extrusion process described in section 1.1. It is therefore desirable to develop an alternative procedure for the production of significant quantities of vitrimer materials. In the following perspective section, we briefly describe a process based on CRE (Continuous Reactive Extrusion) which could respond to the aforementioned requirement and could be transferred to the industrial scale.

\section{Perspective: production of PBT pre-vitrimers by Continuous Reactive Extrusion} (CRE)

The production of fully cross-linked vitrimers by CRE is a very challenging task because of the high viscosity of these materials in the molten state. To our knowledge, this has only been achieved for vitrimers with specific properties which were deliberately designed to have a very high rate of chemical exchange..$^{42}$ In section 3.1 , we describe how CRE can be used to produce materials for which the reaction time in the extruder is reduced so that the crosslinking reaction is not finished at the extruder outlet. In the following, these materials are called "pre- 
vitrimers". In section 3.2, we show that the crosslinking reaction can resume by a simple curing process above $T_{m}$ leading to the final vitrimer. Our overall approach is rather straightforward but to our knowledge this is the first time the validity of such a simple CRE-based process to produce vitrimers has been demonstrated.

\subsection{Pre-vitrimer production by Continuous Reactive Extrusion}

The samples of PBT-based pre-vitrimers were prepared using a single-step reactive extrusion. Well-dried PBT pellets were introduced trough the feed hopper of the extruder via a volumetric feeder (K-Tron). A syringe pump (PS KDS-100) was used to add a controllable volume flow in the form of a steady flow of drops of the DGEBA/catalyst/antioxidant solution (figure 11) farther in the extruder. The mass proportions of the DGEBA/catalyst/antioxidant solutions were 10/1/1.

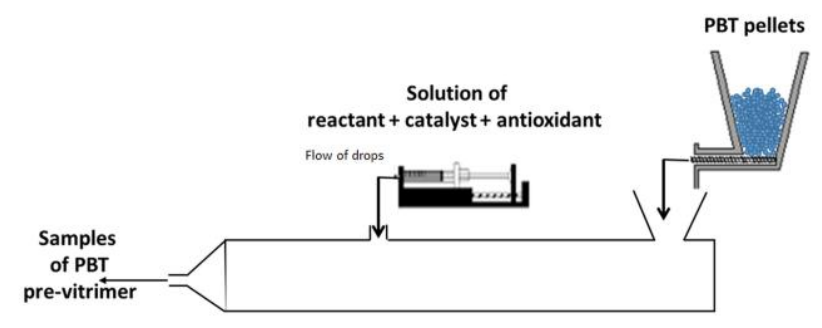

Figure 11 Scheme of the process with the consecutive feedings of the PBT pellets and solution of reactants premixed with catalyst and antioxidant powders.

The extruder used to carry out the crosslinking reaction was a modular intermeshing co-rotating twin-screw extruder TSE 24 from Thermo Scientific ${ }^{\mathrm{TM}}$ with a screw diameter, D, of $24 \mathrm{~mm}$ and an L/D ratio of 40 (where $\mathrm{L}$ is the length of the screw). The screw profile was designed to consecutively allow the melting of the PBT and the further mixing of the melted PBT with the reactants (DGEBA+catalyst+antioxidant) thanks to one or two zones of kneading blocks. The temperature of the barrel was constant at $270^{\circ} \mathrm{C}$ all along the portion of the screws where the reaction effectively took place. During the preliminary experiments, the screw rotation speed was varied from $50 \mathrm{rpm}$ to $300 \mathrm{rpm}$ and the locations of the feeding of PBT pellets and solution were modified. The objective of this optimization work was to reduce the reaction time to avoid the screw blockage caused when the melt viscosity is too high (figure S11). Figure S12 shows the final screw and temperature profiles along with the feeding 
locations of PBT and the solution of reactant (pre-mixed with the catalyst and antioxidant powders) determined after optimization of the operating process parameters. The reaction time in the extruder is about $200 \mathrm{~s}$.

The flow rate of the PBT was $1 \mathrm{~kg} / \mathrm{h}$. Three "pre-vitrimers" were produced by CRE. The syringe pump flow rates respectively corresponded to $1 \%, 1.3 \%$ and $1.6 \%$ for the pre-vitrimers DGEBA mass fraction. Table 4 also gives the DGEBA solution mass flow rate as well as the torque and pressure measured at the die during the preparation of

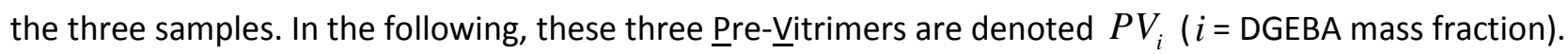

\begin{tabular}{|c|c|c|c|c|}
\cline { 2 - 5 } & $\begin{array}{c}\text { Flow rate } \\
\text { of DGEBA } \\
\text { solution } \\
(\mathrm{g} / \mathrm{min})\end{array}$ & $\begin{array}{c}\text { DGEBA } \\
\text { mass } \\
\text { fraction } \\
\text { in pre- } \\
\text { vitrimers }\end{array}$ & $\begin{array}{c}\text { Torque } \\
(\mathrm{Nm})\end{array}$ & $\begin{array}{c}\text { Pressure } \\
\text { at the } \\
\text { die } \\
\text { (bars })\end{array}$ \\
\hline$P V_{1}$ & 0.17 & $1 \%$ & 12 & 11 \\
\hline$P V_{1.3}$ & 0.22 & $1.3 \%$ & 19 & 14 \\
\hline$P V_{1.6}$ & 0.28 & $1.6 \%$ & 22 & 19 \\
\hline
\end{tabular}

Table 4 Operating conditions for the preparation of PBT pre-vitrimer samples.

\subsection{Gelation and curing of the pre-vitrimers obtained by CRE}

After solidification at room temperature, the three pre-vitrimers $\left(P V_{1}, P V_{1.3}\right.$. and $\left.P V_{1.6}\right)$ were ground to a characteristic size very similar to PBT pellets (a few millimetres) and introduced in the rheometer at $270^{\circ} \mathrm{C}$. The test was launched when melting was observed. The storage $\left(G^{\prime}\right)$ and loss $\left(G^{\prime \prime}\right)$ shear modulus evolutions are shown in figure 12. The three curves for $G^{\prime}$ as well as the three curves for $G^{\prime \prime}$ show the same overall trends but are shifted - the higher the DGEBA concentration, the higher the storage and loss moduli. 


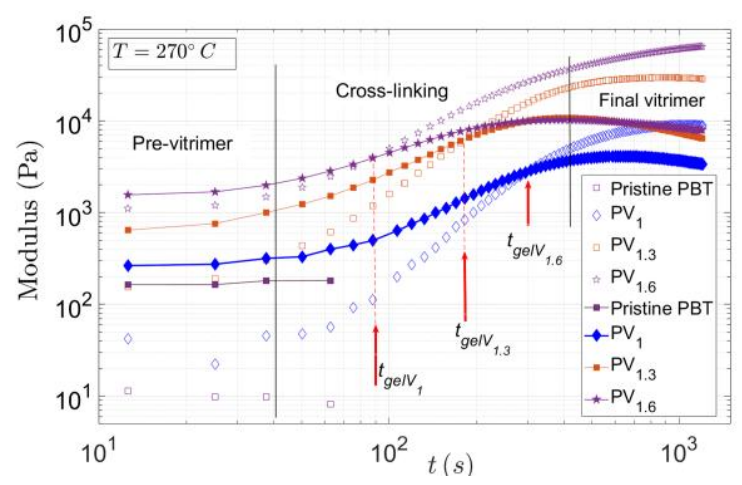

Figure 12 Time dependence of the storage $G^{\prime}$ (open symbols) and loss shear moduli $G$ " (filled symbols) for $P V_{1}$,

$P V_{1.3}$. and $P V_{1.6}$ (pre-vitrimers obtained at the extruder outlet). The rheometer temperature is $T=270^{\circ} \mathrm{C}$.

At the beginning of the test, $G^{\prime}$ is smaller than $G^{\prime \prime}$ for the three pre-vitrimers, which indicates that the materials still have a predominantly "liquid-behaviour" and are therefore again likely to flow. The materials are approximately in the same state as at the extruder outlet. Within $10-40 s$, the complex viscosities $\left(\left|G^{\prime}+i G^{\prime \prime}\right| / \omega\right.$, see Supporting Information, figure S13) are respectively smaller than $3.210^{2}, 1.010^{3}$ and $2.510^{3}$ Pa.s for $P V_{1}, P V_{1.3}$. and $P V_{1.6}$. In this time interval and for this viscosity range, polymer injection remains very easy. Next, within $0.5 \times 10^{2}-0.5 \times 10^{3} s$, an increase of the moduli can be observed and the $G^{\prime}$ and $G$ " curves cross each over respectively for $t \approx 90 s\left(P V_{1.6}\right), t \approx 185 s\left(P V_{1.3}\right)$ and $t \approx 290 s\left(P V_{1}\right)$. We can therefore estimate that gelation takes place in this time range. Thereafter $\left(t>0.5 \times 10^{3} s\right), G^{\prime}$ and $G^{\prime \prime}$ simultaneously become nearly constant, which strongly suggests that the crosslinking reaction leading to the final vitrimer (that could be called $V_{i}$ as in section 2) is approximately over. However, at the end of the test, the $G^{\prime \prime}$ modulus decreases slightly. The decrease of the storage and loss moduli can be attributed to polymer degradation. ${ }^{27}$ The results of the DSC experiments obtained from the pre-vitrimers are summarized in the section 2 of the SI. As for the vitrimers produced with the micro-compounder (see section 2.1), the crystallinity degree is close to that of the pristine PBT.

The overall conclusion of the experiments reported in section 3 is that the CRE process can be considered as a preliminary mixing stage. The residence time in the extruder and the reactive agents input flow rate have to be short enough to avoid screw blocking but there is a possible range of variability to set a desired "pre-vitrimer". 
The reported observations from the rheometric curves show that raising the temperature of the pre-vitrimer to $270^{\circ} \mathrm{C}$ restarts the crosslinking reaction. This is an important point for the development of an industrial process. The pre-vitrimers could be initially produced by CRE in the form of storable and portable pellets. Next, the material could be shaped using fast injection molding processes. Vitrimer parts with optimal advancement in the crosslinking reaction could finally be obtained by curing at $270^{\circ} \mathrm{C}$.

\section{Conclusion}

In the main part of the paper, we presented an experimental investigation of the plastic deformation mechanisms in vitrimers obtained from a PBT precursor. With monotonic tensile tests carried out at temperatures ranging from the glass transition to the melting point, the development of plasticity in the studied vitrimers was found to differ drastically from that of both their PBT precursor and of the other semi-crystalline polymers. The vitrimer specimens were found to be able to deform plastically without necking as the strain remains uniform over the entire specimen throughout tests up to high strain levels. The suppression of necking is a consequence of the strain-hardening increase caused by vitrimer crosslinking. With creep tests, it was also possible to demonstrate the significant improvement of the vitrimers' dimensional stabilities compared to their PBT precursor.

These results are of significant practical interest. Previous studies have shown that a part in the PBT vitrimer retains its original shape in the event of temporary overheating above the melting point (for example $30 \mathrm{~min}$ at $250^{\circ} \mathrm{C}$ ) while the same part in unmodified PBT drips. ${ }^{13}$ Poly(butylene terephthalate) is present in moulded parts such as connector sheaths, kitchen utensils, cogwheels, household appliance housings, etc and such parts must withstand heat even in normal use conditions. Our study has shown that even below the melting point the PBT vitrimer offers enhanced dimensional stability in comparison to pristine PBT.

Our results are very promising and highlight the need for comprehensive systematic studies of vitrimers' solid mechanical properties. This objective requires a way to be found to achieve rapid mass production of this type of material. With this perspective in mind, we have proposed a synthesis process in which materials we named "previtrimer" are first produced by continuous reactive extrusion. In our feasibility study, the precursor was a PBT but the procedure principle is not specific to this polymer. At the extruder outlet, the crosslinking reaction is not over which makes it possible to avoid extruder blockage. During the second stage of the process, the crosslinking 
reaction is simply restarted by curing above the melting temperature until the final vitrimer is obtained. However, transferring the process to industry will require careful control of reaction kinetics. The gelation time must be sufficiently long for the "pre-vitrimers" to retain the ability to flow at the extruder outlet but, on the other hand, a gelation time which is too long may excessively lengthen the second stage of the process during which the crosslinking reaction ends. Furthermore, above the melting temperature, the bond migration mechanism in highly crosslinked vitrimers must be sufficiently fast to allow the easy shaping and recycling of the material. However, in normal use, high bond migration speeds could be detrimental to the material's dimensional stability. Overall, the reaction kinetics can be controlled by adjusting the chemical composition. Controlling the catalyst activity is of paramount importance in view of developing processable semi-crystalline-based vitrimers with fast crosslinking in the melt, compatible with the extrusion time and sufficiently low exchange rate at lower temperatures to get net improvement of mechanical properties in the range of PBT usage.

\section{Acknowledgements}

We thank Mickael Pomes-Hadda for technical assistance with TGA. F. T. acknowledges financial support from the ANR through the MATVIT project (ANR-18-CE06-0026-01). This research used resources of the Advanced Photon Source, a U.S. Department of Energy (DOE) Office of Science User Facility operated for the DOE Office of Science by Argonne National Laboratory under Contract DE-AC02-06CH11357. We thank Steven J. Weigand of the Advanced Photon Source for performing our measurements at beamline DND-CAT 5ID-D.

\section{Associated Content}

\section{Supporting Information}

Further information on true stresses and strains as well as on the strain-hardening coefficient. Additional results obtained during tensile tests. DSC, TGA and X-ray diffraction data.

\section{References}

[1] Montarnal, D., Capelot, M., Tournilhac, F., \& Leibler, L. (2011). Silica-like malleable materials from permanent organic networks. Science, 334(6058), 965-968. 
[2] Capelot, M., Montarnal, D., Tournilhac, F., \& Leibler, L. (2012a). Metal-catalyzed transesterification for healing and assembling of thermosets. Journal of the american chemical society, 134(18), 7664-7667.

[3] Capelot, M., Unterlass, M. M., Tournilhac, F., \& Leibler, L. (2012b). Catalytic control of the vitrimer glass transition. ACS Macro Letters, 1(7), 789-792.

[4] Denissen, W., Winne, J. M., \& Du Prez, F. E. (2016). Vitrimers: permanent organic networks with glass-like fluidity. Chemical science, 7(1), 30-38.

[5] Van Zee, N. J., \& Nicolaÿ, R. (2020). Vitrimers: Permanently crosslinked polymers with dynamic network topology. Progress in Polymer Science, 101233.

[6] Kloxin, C. J., \& Bowman, C. N. (2013). Covalent adaptable networks: smart, reconfigurable and responsive network systems. Chemical Society Reviews, 42(17), 7161-7173.

[7] Scheutz, G. M., Lessard, J. J., Sims, M. B., \& Sumerlin, B. S. (2019). Adaptable crosslinks in polymeric materials: resolving the intersection of thermoplastics and thermosets. Journal of the American Chemical Society, 141(41), 16181-16196.

[8] Denissen, W., Rivero, G., Nicolaÿ, R., Leibler, L., Winne, J. M., \& Du Prez, F. E. (2015). Vinylogous urethane vitrimers. Advanced Functional Materials, 25(16), 2451-2457.

[9] Arnebold, A., Wellmann, S., \& Hartwig, A. (2016). Network dynamics in cationically polymerized, crosslinked epoxy resins and its influence on crystallinity and toughness. Polymer, 91, 14-23.

[10] Azcune, I., \& Odriozola, I. (2016). Aromatic disulfide crosslinks in polymer systems: Self-healing, reprocessability, recyclability and more. European Polymer Journal, 84, 147-160.

[11] Denissen, W., Droesbeke, M., Nicolaÿ, R., Leibler, L., Winne, J. M., \& Du Prez, F. E. (2017). Chemical control of the viscoelastic properties of vinylogous urethane vitrimers. Nature communications, 8(1), 1-7.

[12] Zhang, L., \& Rowan, S. J. (2017). Effect of sterics and degree of cross-linking on the mechanical properties of dynamic poly (alkylurea-urethane) networks. Macromolecules, 50(13), 5051-5060.

[13] Demongeot, A., Groote, R., Goossens, H., Hoeks, T., Tournilhac, F., \& Leibler, L. (2017). Cross-linking of poly (butylene terephthalate) by reactive extrusion using Zn (II) epoxy-vitrimer chemistry. Macromolecules, 50(16), 6117-6127. 
[14] Hendriks, B., Waelkens, J., Winne, J. M., \& Du Prez, F. E. (2017). Poly (thioether) vitrimers via transalkylation of trialkylsulfonium salts. ACS Macro Letters, 6(9), 930-934.

[15] Tang, J., Wan, L., Zhou, Y., Pan, H., \& Huang, F. (2017). Strong and efficient self-healing adhesives based on dynamic quaternization cross-links. Journal of Materials Chemistry A, 5(40), 21169-21177.

[16] Obadia, M. M., Jourdain, A., Cassagnau, P., Montarnal, D., \& Drockenmuller, E. (2017). Tuning the Viscosity Profile of Ionic Vitrimers Incorporating 1, 2, 3-Triazolium Cross-Links. Advanced Functional Materials, 27(45), 1703258.

[17] Stukenbroeker, T., Wang, W., Winne, J. M., Du Prez, F. E., Nicolaÿ, R., \& Leibler, L. (2017).

Polydimethylsiloxane quenchable vitrimers. Polymer Chemistry, 8(43), 6590-6593.

[18] Zhang, S., Pan, L., Xia, L., Sun, Y., \& Liu, X. (2017). Dynamic polysulfide shape memory networks derived from elemental sulfur and their dual thermo-/photo-induced solid-state plasticity. Reactive and Functional Polymers, 121, 8-14.

[19] Snyder, R. L., Fortman, D. J., De Hoe, G. X., Hillmyer, M. A., \& Dichtel, W. R. (2018). Reprocessable aciddegradable polycarbonate vitrimers. Macromolecules, 51(2), 389-397.

[20] Lessard, J. J., Garcia, L. F., Easterling, C. P., Sims, M. B., Bentz, K. C., Arencibia, S., \& Sumerlin, B. S. (2019). Catalyst-free vitrimers from vinyl polymers. Macromolecules, 52(5), 2105-2111.

[21] Self, J. L., Dolinski, N. D., Zayas, M. S., Read de Alaniz, J., \& Bates, C. M. (2018). Brønsted-Acid-Catalyzed Exchange in Polyester Dynamic Covalent Networks. ACS Macro Letters, 7(7), 817-821.

[22] Spiesschaert, Y., Guerre, M., Imbernon, L., Winne, J. M., \& Du Prez, F. (2019). Filler reinforced polydimethylsiloxane-based vitrimers. Polymer, 172, 239-246.

[23] Lu, Y. X., Tournilhac, F., Leibler, L., \& Guan, Z. (2012). Making insoluble polymer networks malleable via olefin metathesis. Journal of the American Chemical Society, 134(20), 8424-8427.

[24] Brutman, J. P., Delgado, P. A., \& Hillmyer, M. A. (2014). Polylactide vitrimers. ACS Macro Letters, 3(7), 607610.

[25] Imbernon, L., Norvez, S., \& Leibler, L. (2016). Stress relaxation and self-adhesion of rubbers with exchangeable links. Macromolecules, 49(6), 2172-2178. 
[26] Röttger, M., Domenech, T., van der Weegen, R., Breuillac, A., Nicolaÿ, R., \& Leibler, L. (2017). High-

performance vitrimers from commodity thermoplastics through dioxaborolane metathesis. Science, 356(6333),

$62-65$.

[27] Caffy, F., \& Nicolaÿ, R. (2019). Transformation of polyethylene into a vitrimer by nitroxide radical coupling of a bis-dioxaborolane. Polymer Chemistry, 10(23), 3107-3115.

[28] Leibler, L., Tournilhac, F., \& Capelot, M., Processable semi-crystalline polymer networks European patent EP2928945 (B1) - pty 2013-12-06

[29] Zhao, S., \& Abu-Omar, M. M. (2019). Catechol-Mediated Glycidylation toward Epoxy Vitrimers/Polymers with Tunable Properties. Macromolecules, 52(10), 3646-3654.

[30] Zhou, Y., Groote, R., Goossens, J. G., Sijbesma, R. P., \& Heuts, J. P. (2019). Tuning PBT vitrimer properties by controlling the dynamics of the adaptable network. Polymer Chemistry, 10(1), 136-144.

[31] Erice, A., Azcune, I., Ruiz de Luzuriaga, A., Ruipérez, F., Irigoyen, M., Matxain, J. M., \& Rekondo, A. (2019). Effect of Regioisomerism on Processability and Mechanical Properties of Amine/Urea Exchange Based Poly (ureaurethane) Vitrimers. ACS Applied Polymer Materials, 1(9), 2472-2481.

[32] Wang, S., Ma, S., Li, Q., Xu, X., Wang, B., Yuan, W., \& Zhu, J. (2019). Facile in situ preparation of highperformance epoxy vitrimer from renewable resources and its application in nondestructive recyclable carbon fiber composite. Green chemistry, 21(6), 1484-1497.

[33] Zhao, Q., Zou, W., Luo, Y., \& Xie, T. (2016). Shape memory polymer network with thermally distinct elasticity and plasticity. Science advances, 2(1), e1501297.

[34] Zheng, N.; Fang, Z.; Zou, W.; Zhao, Q.; Xie, T. Thermoset Shape-Memory Polyurethane with Intrinsic Plasticity Enabled by Transcarbamoylation. Angew. Chem., Int. Ed. 2016, 55, 11421-11425.

[35] Pei, Z., Yang, Y., Chen, Q., Wei, Y., \& Ji, Y. (2016). Regional shape control of strategically assembled multishape memory vitrimers. Advanced Materials, 28(1), 156-160.

[36] Arnebold, A., \& Hartwig, A. (2016). Fast switchable, epoxy based shape-memory polymers with high strength and toughness. Polymer, 83, 40-49.

[37] Zhou, Y., Goossens, J. G., Sijbesma, R. P., \& Heuts, J. P. (2017). Poly (butylene terephthalate)/glycerol-based vitrimers via solid-state polymerization. Macromolecules, 50(17), 6742-6751. 
[38] Tellers, J., Pinalli, R., Soliman, M., Vachon, J., \& Dalcanale, E. (2019). Reprocessable vinylogous urethane cross-linked polyethylene via reactive extrusion. Polymer Chemistry, 10(40), 5534-5542.

[39] Zych, A., Pinalli, R., Soliman, M., Vachon, J., \& Dalcanale, E. (2020). Polyethylene vitrimers via silyl ether exchange reaction. Polymer, 122567.

[40] Chabert, E., Vial, J., Cauchois, J-P., Mihaluta, M., Tournilhac, F., (2016) Multiple welding of long fiber epoxy vitrimer composites, Soft Matter, 12, 4838.

[41] Snijkers, F., Pasquino, R., \& Maffezzoli, A. (2017). Curing and viscoelasticity of vitrimers. Soft Matter, 13(1), 258-268.

[42] Taplan, C., Guerre, M., Winne, J. M., \& Du Prez, F. E. (2020). Fast processing of highly crosslinked, lowviscosity vitrimers. Materials Horizons, 7, 104-110.

[43] Radusch, H., J., Poly(Butylene Terephthalate) in Handbook of Thermoplastic Polymers: Homopolymers, copolymers, Blends, and Composites, Chapter 8, Fakirov, S. ed., WILEY-VCH Verlag GmbH, Weinheim 2002 [44] datasheet Crastin ${ }^{\circledR}$ S600F40 NC010 CAMPUS Datasheet https://www.campusplastics.com/material/pdf/127529?sLg=en

[45] Van Krevelen, D. W. (1975). Some basic aspects of flame resistance of polymeric materials. Polymer, 16(8), $615-620$.

[46] Vincent, P. I. (1960). The necking and cold-drawing of rigid plastics. Polymer, 1, 7-19.

[47] Séguéla, R. (2007). On the Natural Draw Ratio of Semi-Crystalline Polymers: Review of the Mechanical, Physical and Molecular Aspects. Macromolecular Materials and Engineering, 292(3), 235-244.

[48] Farge, L., André, S., \& Boisse, J. (2018). Use of Digital Image Correlation to study the effect of temperature on the development of plastic instabilities in a semi-crystalline polymer. Polymer, 153, 295-304.

[49] Ye, J., André, S., \& Farge, L. (2015). Kinematic study of necking in a semi-crystalline polymer through 3D Digital Image Correlation. International Journal of Solids and Structures, 59, 58-72.

[50] Seguela, R. (2005). Critical review of the molecular topology of semicrystalline polymers: The origin and assessment of intercrystalline tie molecules and chain entanglements. Journal of Polymer Science Part B: Polymer Physics, 43(14), 1729-1748. 
[51] Schrauwen, B. A., Janssen, R. P., Govaert, L. E., \& Meijer, H. E. (2004). Intrinsic deformation behavior of semicrystalline polymers. Macromolecules, 37(16), 6069-6078.

[52] Pawlak, A., \& Galeski, A. (2005). Plastic deformation of crystalline polymers: the role of cavitation and crystal plasticity. Macromolecules, 38(23), 9688-9697.

[53] Bartczak, Z. (2005). Effect of chain entanglements on plastic deformation behavior of linear polyethylene. Macromolecules, 38(18), 7702-7713.

[54] Demongeot, A., Mougnier, S. J., Okada, S., Soulié-Ziakovic, C., \& Tournilhac, F. (2016). Coordination and catalysis of Zn 2+ in epoxy-based vitrimers. Polymer Chemistry, 7(27), 4486-4493.

[55] Unwin, A. P., Duckett, R. A., Ward, I. M., Collins, T. L. D., Sweeney, J., \& Coates, P. D. (2002). Suppression of necking in polyethylene. Journal of applied polymer science, 86(12), 3135-3147.

[56] Khonakdar, H. A., Morshedian, J., Wagenknecht, U., \& Jafari, S. H. (2003). An investigation of chemical crosslinking effect on properties of high-density polyethylene. Polymer, 44(15), 4301-4309.

[57] Nielsen, L. E. (1969). Cross-linking-effect on physical properties of polymers. Journal of Macromolecular Science, Part C, 3(1), 69-103.

[58] Zhang, W., Li, J., Shang, Y., Li, H., Jiang, S., \& An, L. (2017). Temperature dependence of tensile behavior in poly (butylene terephthalate) with different crystallinity. Materials \& Design, 129, 143-150. 